\title{
Cardiovascular comorbidity in patients with restless legs syndrome: current perspectives
}

This article was published in the following Dove Press journal: Journal of Parkinsonism and Restless Legs Syndrome

3 May 2017

Number of times this article has been viewed

\section{Noel J Vargas-Pérez \\ Kanika Bagai \\ Arthur S Walters}

Department of Neurology, Vanderbilt University Medical Center, Nashville, TN, USA
Correspondence: Arthur S Walters Department of Neurology,

A-0I I8, Medical Center North,

II6I 2 Ist Avenue S., Nashville,

TN 37232-255I, USA

Tel +l 6153220283

Fax + I 6159360223

Email arthur.walters@vanderbilt.edu
Introduction: Restless legs syndrome (RLS) is a sensorimotor neurological disorder associated with poor quality of life. Growing evidence links RLS and periodic limb movement in sleep (PLMS) with increased risk of cardiovascular and cerebrovascular disease. This article reviews the association of RLS and PLMS with cardiovascular disease (CVD).

Methods: PubMed and Medline database (1990 to July 2016) were searched for the terms "restless legs," "restless legs syndrome," "periodic limb movements," "periodic limb movements in sleep" cross-referenced with "cardiovascular disease," "heart disease," "coronary artery disease," "coronary heart disease," "heart arrhythmia," "heart failure," "congestive heart failure," "echocardiogram," "echocardiographic," "hypertension," "high blood pressure," "cerebrovascular disease," "stroke," “autonomic nervous system," "heart rate," "heart rate variability," "hypoxia," "microcirculation," "oxidative stress," "inflammation," "chronic kidney disease," "end-stage renal disease," "renal disease," "hemodialysis," "multiple sclerosis," "Parkinson," "Parkinson's," "iron deficiency anemia," and "mortality." Other relevant articles from the reference list of the above-matched manuscripts were also reviewed. Studies that did not specify the diagnostic criteria for RLS or manuscripts in languages other than English were excluded. Articles with emphasis in RLS secondary to pregnancy were not included in this manuscript.

Results: Eighty-six original articles were included in this review. Although mixed results were found regarding the association of RLS and PLMS with CVD, hypertension, stroke and mortality, an informal review of the literature does suggest that the bulk of the evidence favors such an association.

Conclusion: The current evidence in general supports the association between RLS/PLMS and CVD. The variability of results likely represent differences in study designs, RLS criteria used, RLS severity, duration of disease, and time of follow-up between the studies. As the association between RLS/PLMS and CVD is not definitive at this time, further suggested studies are outlined. Keywords: restless legs syndrome, periodic limb movements in sleep, cardiovascular disease, heart disease, hypertension, stroke, chronic kidney disease

\section{Background}

Cardiovascular diseases (CVD) have accounted for more deaths than any other major cause of death in the United States. CVD accounted for $\sim 17.3$ million deaths per year in 2013. ${ }^{1}$ Approximately 2200 Americans die of CVD each day, that is, 1 death in every 40 s on average. Based on 2013 mortality data, CVD is listed as the underlying cause of death in $\sim 1$ of every 3 deaths in the United States. The death rate attributable to CVD was 222.9 per $100,000 .^{1}$

Approximately 795,000 people experience a new or recurrent stroke every year. On an average in every $40 \mathrm{~s}$, someone in the United States has a stroke and, in every 
$4 \mathrm{~min}$, someone dies due to stroke. In addition, stroke is a leading cause of serious long-term disability in the United States. It is estimated that CVD and stroke cost $\sim \$ 316.6$ billion annually in the United States while considering both direct and indirect costs. ${ }^{1}$

CVD, including stroke, share common risk factors such as hypertension, hyperlipidemia, diabetes mellitus (DM), smoking, obesity, and obstructive sleep apnea (OSA). More recently, restless legs syndrome (RLS) and periodic limb movement in sleep (PLMS) have gained considerable attention because of their possible association with CVD. ${ }^{2-8}$ This review focuses on the association between RLS and/or PLMS and CVD.

\section{Introduction}

RLS is a sensorimotor sleep disorder associated with poor quality of life and sleep disruption. The affected persons describe a discomfort or irresistible urge to move the legs. Many forms of discomfort may be described including pain. In some cases, no discomfort is described but only an urge to move the legs. Less commonly, the arms may be involved. ${ }^{9}$ The International Restless Legs Syndrome Study Group (IRLSSG) criteria for RLS were initially published in $1995,{ }^{10}$ then in 2003, and last updated in $2014 .{ }^{11}$ In the last update, a fifth essential criterion to exclude mimics, as well as specifiers for clinical significance and clinical course, was added. Pediatric RLS criteria were also merged with the adult diagnostic criteria. A summarized version of these updated IRLSSG criteria are presented in Table 1.

Sleep onset and maintenance complaints are commonly associated with RLS. Disturbed sleep is reported in $60 \%-90 \%$ affected individuals and is usually the reason for seeking medical care. ${ }^{9,12}$

Population-based studies have estimated a prevalence of RLS between 5\% and 10\% in Europe and North America. ${ }^{9,13}$
The prevalence of RLS is higher in women and increases with age. ${ }^{14}$

PLMS are reported to occur in $80 \%-90 \%$ of patients with RLS. ${ }^{9}, 15$ PLMS consist of highly stereotyped movements typically affecting the lower extremities and less often the upper extremities. PLMS involve a combination of the big toe extension, partial ankle dorsiflexion, knee flexion, and less often the flexion of the hip. ${ }^{9}$ When such movements occur with a consistent periodicity, these are called periodic limb movement (PLM) series (Figure 1). ${ }^{16}$

Although not well defined, subtypes of RLS have been described. The early onset type has been described as starting before 45 years of age, which tends to be more familial and tends to progress slower than late-onset RLS. ${ }^{17}$ Other subclassifications describe RLS as primary (idiopathic) or secondary RLS when it is associated with pregnancy, iron deficiency anemia (IDA), chronic renal failure, or other conditions. ${ }^{2}$

The exact pathophysiology of RLS remains unclear. Various mechanisms including (individually or in combination) genetic predisposition, dopaminergic dysfunction, brain iron insufficiency, activation of hypoxic pathways, glutamatergic system involvement, opioid system dysfunction, and a few others have been proposed. ${ }^{18}$ Although some unfilled gaps remain, the theory with most evidence is the iron deficiency-dopamine metabolic theory, where iron deficiency in brain along with alteration in dopaminergic function seem to play important roles in the etiology and manifestations of RLS. Studies of cerebrospinal fluid, ${ }^{18}$ brain imaging showing reduced regional iron in brain and altered functions of brain dopamine, ${ }^{18}$ autopsy studies, and the clinical efficacy of dopamine receptor agonists and iron replacement therapy showing significant improvement of RLS symptoms support (at least partially) the aforementioned theories. ${ }^{18}$

Table I Summarized International Restless Legs Syndrome Study Group consensus diagnostics criteria for restless legs syndrome (RLS), 2014 update

Essential diagnostic criteria (all must be met):

I. An urge to move the legs usually but not always accompanied by uncomfortable and unpleasant sensations in the legs*

2. The urge to move the legs begins or worsens during periods of rest or inactivity

3. The urge to move the legs is partially or totally relieved by movement, such as walking or stretching

4. The urge to move the legs occurs or is worse in the evening or night than during the day

5. Above features are not solely accounted for symptoms primary to another medical or a behavioral condition (eg, myalgia, venous stasis, leg edema, arthritis, leg cramps, positional discomfort, habitual foot tapping)

Specifiers for clinical course of RLS":

A. Chronic-persistent RLS: symptoms occur on average at least twice weekly in the past year

B. Intermittent RLS: symptoms occur on average $<2 /$ week in the past year, with at least five lifetime events

Specifier for clinical significance of RLS:

The symptoms cause significant distress or impairment in social, occupational, educational or other important areas of functioning by their impact on sleep, energy/vitality, daily activities, behavior, cognition or mood.

Notes: *For children, the description of these symptoms should be in the child's own words. "The clinical course criteria apply neither for pediatric cases nor for some special cases of provoked RLS such as pregnancy or drug-induced RLS 


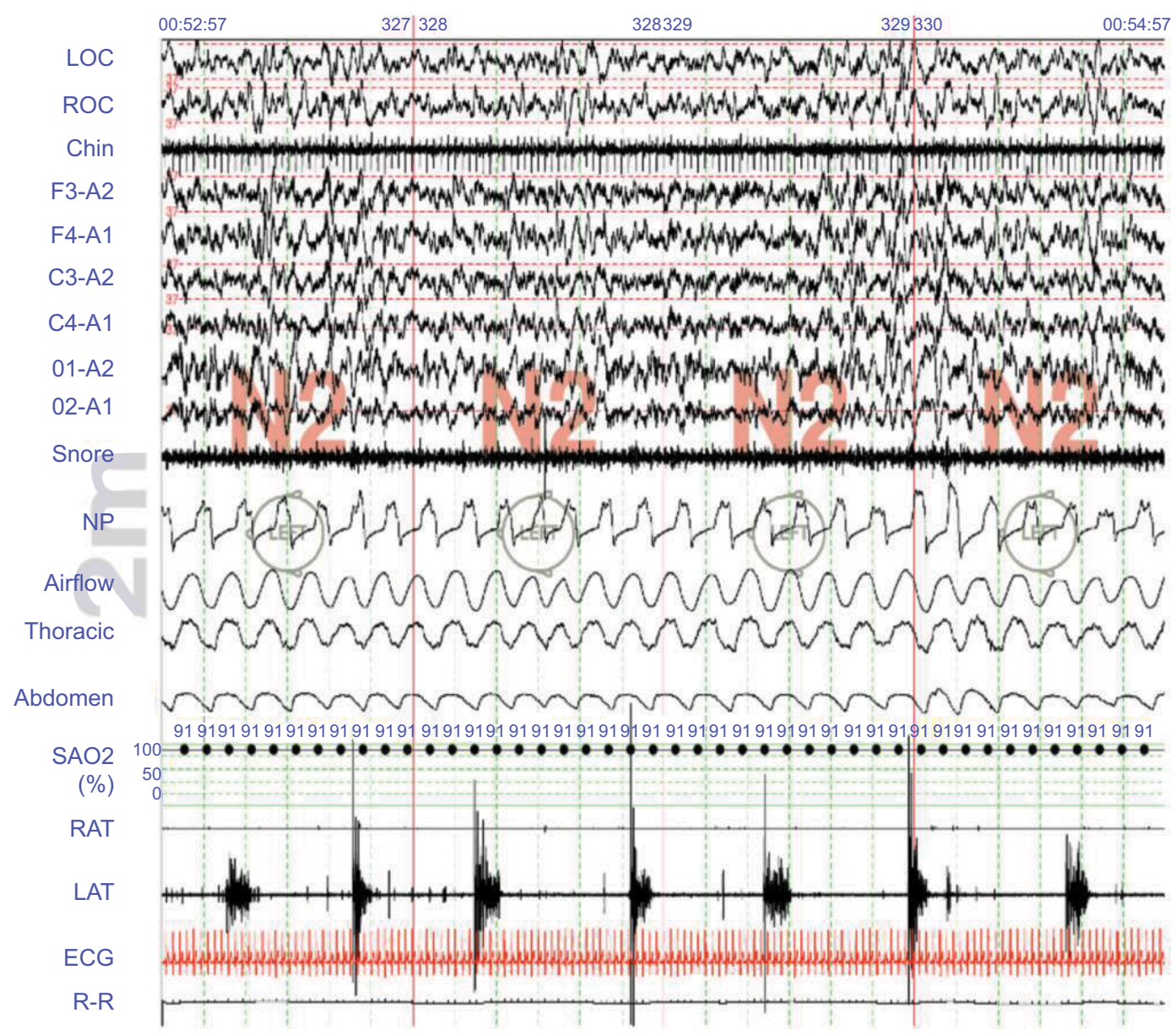

Figure I Periodic limb movement in sleep. Example of a 2 minute epoch of an adult patient with periodic limb movements in sleep (PLMS).

Abbreviations: LOC, left outer canthus; ROC, right outer canthus; chin, chin electromyogram (EMG) channel; $F 3$ and F4, left and right frontal electroencephalogram (EEG) channels; C3 and C4, left and right central EEG channels; OI and O2, left and right frontal EEG channels; AI and A2, left and right ear EEG channels; NP, nasal pressure transducer; Airflow, oronasal thermal airflow sensor; Thoracic and Abdomen, dual thoracoabdominal respiratory plethysmography (RIP); SAO2, pulse oximetry; RAT, right anterior tibialis muscle EMG channel; LAT, left anterior tibialis muscle EMG channel; ECG, electrocardiogram; R-R, RR interval.

\section{Methods}

This review included original studies with data for the association between RLS/PLMS and CVD. The authors used PubMed and Medline database (1990 to July 2016) to search for the terms "restless legs," "restless legs syndrome," "periodic limb movements," "periodic limb movements in sleep' cross-referenced with "cardiovascular disease," "heart disease," "coronary artery disease," "coronary heart disease," "heart arrhythmia," "heart failure," "congestive heart failure," "echocardiogram," "echocardiographic," "hypertension," "high blood pressure," "cerebrovascular disease," "stroke," "autonomic nervous system," "heart rate," "heart rate variability," "hypoxia," "microcirculation," "oxidative stress," "inflammation," "“chronic kidney disease," "end-stage renal disease," "renal disease," "hemodialysis," "multiple sclerosis," "Parkinson," "Parkinson's," "iron deficiency anemia," and "mortality." Other relevant papers from the reference list of the above-matched manuscripts were also reviewed and included when pertinent. Studies that did not specify diagnostic criteria for RLS or any of the four diagnostic criteria specified by IRLSSG were not included. In addition, studies published only in abstract format, other languages than English, or publications with emphasis in RLS secondary to pregnancy were also excluded.

\section{Association of RLS/PLMS with CVD and hypertension}

RLS and PLMS are associated with several medical and psychiatric disorders. Conditions associated with RLS include attention-deficit and hyperactive disorder, narcolepsy, Parkinson disease (PD), multiple sclerosis (MS), peripheral neuropathy, OSA, chronic kidney disease (CKD), DM, rheumatoid arthritis, mood disorders, and anxiety disorders. ${ }^{9}$ Common sleep disorders associated with PLMS include OSA, narcolepsy, and REM sleep behavior disorder. ${ }^{9}$ More 
recently, CVD, including hypertension, coronary heart disease (CHD), congestive heart failure (CHF), heart transplant, and stroke are thought to be more prevalent in patients with RLS and PLMS. ${ }^{2-8}$

\section{RLS/PLMS and cardiovascular diseases}

RLS and PLMS have been associated with CVD, hypertension and stroke. The mechanism of how RLS or PLMS leads to increased risk for the development of CVD is still not clearly defined. Multiple studies exploring the association of RLS/PLMS with CVD have been published in the last decades. In this section, the evidence of the association of RLS with CVD will be presented. Table S1 details the studies discussed in this section concerning CVD.

Most studies reporting association between RLS/PLMS and increased cardiovascular risk are epidemiological studies. In 2002 a cross-sectional study of 18,980 subjects (aged 15 to 100 years old) found association of RLS with self-reported heart disease (adjusted odds ratio [aOR] 1.41; 95\% confidence interval $[\mathrm{CI}] 1.06-1.88 ; P<0.05)$. This study was published 1 year prior to the publication of an updated version of the IRLSSG criteria in 2003. ${ }^{19}$ Similarly, Winkelman et al using data from the Wisconsin Sleep Cohort $(\mathrm{N}=2,831)$ noted that in RLS patients presenting daily symptoms the prevalence of CVD was higher than those without RLS symptoms (aOR $=2.58 ; 95 \% \mathrm{CI}, 1.38-4.84)$. In this study strict IRLSSG criteria were not used but other modified questions for RLS were used. ${ }^{20}$ The same authors found significant increase in self-reported coronary artery disease (CAD) and CVD in 1,559 men and 1,874 women using the data from the Sleep Heart Health Study. Of note, there was a stronger correlation of $\mathrm{CAD} / \mathrm{CVD}$ in patients with RLS symptoms with a frequency $\geq 16$ times/month. However, this association was lost in subjects with less severe RLS. ${ }^{21}$ In a prospective study of more than 70,000 women free of CHD and stroke at baseline, Li et al found that women with RLS duration $\geq 3$ years had more non-fatal myocardial infarction (adjusted HR [aHR] = 1.80; 95\%CI 1.07-3.01) compared with women with an RLS duration $<3$ years. ${ }^{22}$ As noted, above studies suggest an increased risk of CVD associated with severity and duration of RLS symptoms. ${ }^{21,22}$

A big scale observational study $(\mathrm{N}=7,392)$ in US Veterans patients ( $93 \%$ male, mean age 59.9 years) found incident RLS to be associated with an almost 4 fold risk of CHD compared with the control cohort. Similar results were obtained after adjusting for insomnia in sensitivity analysis. ${ }^{23}$ In a largescale study by Van Den Eeden et $\mathrm{al}^{2}$ with a 473,358 personyear follow-up (mean follow-up time: 3.91 years), subjects were classified as having primary or secondary RLS (defined as anemia, pregnancy, and renal disease), and both the groups were compared with controls. Primary RLS was not associated with increased risk of CAD or CVD, but the secondary RLS group showed increased risk of CVD ( $\mathrm{HR}=1.33 ; 95 \%$ CI, 1.21-1.46), CAD (HR =1.40; 95\%CI, 1.25-1.56), and hypertension $(\mathrm{HR}=1.28 ; 95 \% \mathrm{CI}, 1.18-1.40)$. However, when the comparison group was matched with the secondary RLS group (in terms of anemia and/or renal failure), the associations of increased CVD, CAD, and hypertension were lost. These results suggest that the increased risk of CVD in secondary RLS is due to the underlying comorbidities but not RLS independently. ${ }^{2}$ Another study of 5,000 women found an association of RLS with self-reported comorbid heart disease $(\mathrm{aOR}=2.13 ; 95 \% \mathrm{CI}, 1.18-3.86) .{ }^{24}$ On the other hand, Koo et al found only a weak association of PLM arousal index $\geq 5 / \mathrm{h}$ with all-cause CVD ( $\mathrm{HR}=1.26 ; 95 \% \mathrm{CI}, 1.01-1.57$; $P$ trend 0.0402 ) but not with CAD or CHD specifically. ${ }^{5}$

Contrary to most studies which have found increased or null association between RLS and heart disease, in the US Physicians' Health Studies I and II ( $\mathrm{N}=22,786$, all men), Winter et al found a negative association between RLS and prevalent myocardial infarction (age- and multivariable adjusted OR $=0.73 ; 95 \% \mathrm{CI}, 0.55-0.97) .{ }^{3}$ This study was limited by a cross-sectional design, self-reported RLS, and a population of all-physician-mostly-white subjects; thus, the results cannot be applied to the general population. Furthermore, there are other studies that have failed to confirm such association of RLS with heart disease, ${ }^{25,26} \mathrm{CVD}$, myocardial infarction, or stroke. ${ }^{4}$

In summary, several large-scale studies have shown an association of RLS with heart disease. A few studies showed no association with RLS, and one study showed a decreased prevalence of myocardial infarction in patients with RLS. ${ }^{3}$ Importantly, there is paucity of longitudinal studies in this topic; most studies are cross-sectional in nature, thus causality cannot be established. The different results noted in these studies may be due to various criteria defining RLS cases, diverse population and age ranges, cross-sectional design of most studies, and relatively short follow-up. Duration of RLS (and age at which RLS symptoms started) is another important factor that could play a role but was not specified in several studies.

\section{RLS/PLMS and hypertension}

Multiple studies have shown an association of RLS with subsequent development of hypertension. Other studies have shown that hypertension may lead to RLS, leading to incongruent data between such associations. Although not 
completely understood, some authors argued that hypertension could be the possible mechanism as to how RLS/PLMS may lead to increased CVD. ${ }^{27-29}$ Multiple studies but not all have demonstrated increased sympathetic activity in RLS/ PLMS leading to higher nocturnal blood pressure (BP), nondipping BP at night, and/or increased 24-hour BP. ${ }^{7,30-34}$ This section reviews the association between hypertension and RLS/PLMS. Table S1 summarizes studies related to RLS and hypertension.

Phillips et al found that patients with hypertension reported more RLS symptoms $(P<0.05)$, using 2 questions for RLS in a telephonic poll interview. ${ }^{25}$ Similarly, a crosssectional study of 18,980 patients $^{19}$ and another study of women $(\mathrm{N}=65,544)$ participating in the Nurses's Health Study $\mathrm{II}^{35}$ found significantly increased odds of hypertension (aOR 1.36 and 1.20, respectively) in RLS patients. In the previous women's study, a dose-response was noted with increased odds of hypertension in RLS symptoms $\geq 15$ times per month $(\mathrm{aOR}=1.41 ; 95 \% \mathrm{CI}, 1.24-1.61)$ compared with those with less frequent symptoms (aOR of 1.06; 95\% CI, $0.94-1.18) .{ }^{35}$ The results were adjusted for age, race, body mass index, physical activity, menopausal status, smoking, use of analgesics, and intake of alcohol, caffeine, folate, and iron levels. In an interesting retrospective cohort study, Van Den Eeden et $\mathrm{al}^{2}$ divided subjects into primary and secondary RLS and compared them with controls $(473,358$ person-year follow-up; mean follow-up time of 3.91 years). In this study, primary RLS was associated with a slight increased risk (aHR 1.19; 95\%CI, 1.12-1.25) and secondary RLS with a more significant risk of hypertension (aHR 1.28; 95\% CI, 1.18-1.40) compared with the control group. Nevertheless, in subsequent analysis, when secondary RLS and control group were matched for comorbidities (anemia and/or renal disease), the risk of hypertension moves to a null value. ${ }^{2}$ In a rural community in Shanghai $(\mathrm{N}=2,941)$, hypertension was associated with RLS (aOR $=4.10 ; 95 \%$ CI, 1.88-8.92; $P<0.001)$. Interestingly, when compared by gender, hypertension was a risk factor for RLS in males but not in females in this study. ${ }^{36}$ Pennestri et al ${ }^{37}$ analyzed PLMS subjects with RLS (N=14) and without RLS $(\mathrm{N}=14)$. They found a significant increase of the heart rate and systolic and diastolic blood pressure (SBP and DBP) during PLMS in both groups. However, the magnitude of increase of such variables was more pronounced in subjects with RLS compared with those without RLS. ${ }^{37}$ PLMS was defined as periodic leg movement index $(\mathrm{PLMI})>5 / \mathrm{h}$ in this study.

As previously stated, PLMS is present in $80 \%-90 \%$ of patients with RLS. ${ }^{9,15}$ There are multiple studies with inconsistent results for the association between hypertension and PLMS (even in the absence of RLS). In a cross-sectional study of 91 hypertensive patients, Espinar-Sierra et $\mathrm{a}^{38}$ found a prevalence of PLMS (using an old version definition) in combined hypertension type I and type II group to be $13 \%$ compared with a prevalence of $36 \%$ in hypertension type III group. The study was limited by a small sample, with only 9 patients in the type I and II hypertension group, and another 9 patients in the type III hypertension group. ${ }^{38} \mathrm{~A}$ cross-sectional study of 314 children (mean age 10.4 years; $62.4 \%$ boys) found that children with PLMS (N=17, PLMI $\geq 5 / \mathrm{h}$ ) had a significantly higher risk for elevated nocturnal DBP $(\mathrm{aOR}=4.83 ; 95 \% \mathrm{CI}, 1.66-14.07)$ and SBP $(\mathrm{aOR}=$ $6.25 ; 95 \%$ CI, 1.87-20.88) than those without PLMS. These results are important, as hypertension in children will likely translate to hypertension in adulthood and a higher risk for CVD development in the future. ${ }^{39}$

Contrary to the above evidence, other studies did not find association between RLS/PLMS and hypertension. In a large-scale prospective cohort study of subjects free of RLS, arthritis, and diabetes at baseline, hypertension was not associated with a higher risk of RLS dvelopment. ${ }^{40}$ In another well-designed study by Högl et al $(\mathrm{N}=701$, age range 50-89 years) in which patients were evaluated in a face-toface interview and through clinical examination, it was found that RLS was not associated with hypertension (HTN), SBP, or DBP after adjustments for age and gender. ${ }^{41}$ In addition, other studies have failed to demonstrate the association between RLS and hypertension..$^{3,4,21,42-43}$ Curiously, and contrary to other studies that have found either an increased or a neutral association between RLS and hypertension, a study by Rothdach et $\mathrm{al}^{44}$ found significantly lower prevalence of hypertension in subjects with RLS compared with those without RLS (5.6\% vs $23.4 \% ; P=0.04)$ in a population of 369 elder participants ( $47.3 \%$ female, mean age 72.7 years). This study was limited by small sample size (36 RLS patients) in which only 2 patients had hypertension. ${ }^{44}$ Finally, Scofield et al did not find any significant difference of self-reported hypertension in subjects with PLMI $>15 / \mathrm{h}$ compared with subjects with lower PLMI ( $\mathrm{N}=592$, mean age 40.6 \pm 12 years, $53 \%$ women). ${ }^{45}$

In summary, there is accumulating evidence to suggest a possible link between RLS and HTN. On the other hand, other studies, including well-designed studies, did not find such association. Regarding PLMS, the evidence presented here is most consistent with an association between PLMS and hypertension. It is not clear whether the increased prevalence of HTN is related to sleep disturbance caused by PLMS or 
increased sympathetic activity in PLMS. However, a recent placebo-controlled trial ${ }^{7}$ treatment of PLMS with rotigotine patch in patients with moderate to severe RLS resulted in the improvement of nocturnal high BP in this population (see "Association between RLS/PLMS and autonomic nervous system alteration" section). Future pharmacologic studies for RLS/PLMS are needed to clarify whether such therapies decrease the risk of developing HTN, and thus CVD in the long term. Future studies must include larger-scale longitudinal studies, not only with dopamine agonists, but with other medications used to treat RLS/PLMS. In addition, BP changes need to be analyzed in the short and long term. A more extensive BP analysis (ie, nocturnal BP, non-dippers, diurnal BP, 24 h BP, daytime BP fluctuations, and BP/heart rate elevation in association with PLMS) as well as BP changes associated with autonomic system alterations can help understand better whether an association between RLS and hypertension exists. The study designs must include well-defined controls, including patients without RLS/PLMS, patients with RLS without treatment, and normotensive patients, to better assess the different effects of pharmacotherapies on the BP. Last, nonpharmacological approaches such as exercise training could effectively reduce RLS/PLMS symptoms in patients with either idiopathic or secondary RLS, ${ }^{46}$ and these alternatives alone or as adjuvant therapy should be explored better in future studies. ${ }^{47-49}$

\section{RLS/PLMS and arrhythmias}

Several studies have been published assessing the association between PLMS and heart arrhythmias. ${ }^{50,51}$ Sleep disruption due to other sleep disorders has been associated with increased prevalence of arrhythmias, including sleep apnea and insomnia. ${ }^{52,53}$ This review presents the evidence concerning RLS/PLMS and heart arrhythmias.

Mirza et al ${ }^{51}$ retrospectively analyzed 373 patients with atrial fibrillation (AF) and clinically suspected RLS. They aimed to evaluate whether PLMS is a risk factor for the progression of AF. The median follow-up period was 33 months. The frequent PLMS group had a higher rate of AF progression compared with the infrequent PLMS group (34\% vs $23 \% ; P=0.01)$. In multivariate analysis, PLMI $>35 / \mathrm{h}$ was an independent predictor of AF progression ( $\mathrm{OR}=2.24$; 95\%CI, 1.33-3.78). In addition, dopaminergic therapy for RLS in patients with frequent PLMS reduced the risk of AF progression. Limitations of the study include that standard IRLSSG diagnostic criteria for RLS were not used and that patients with OSA were not excluded from the study. However, the mean apnea/hypopnea index (AHI) was similar between the two groups. ${ }^{51}$ In a cross-sectional study of 2,793 community-dwelling older men, Koo et al found no significant associations between PLMI and PLM arousal index with ventricular or atrial arrhythmias (after adjusting for potential confounders). ${ }^{50}$

In summary, there are limited data between the association of PLMS and arrhythmias. One study suggests association of PLMS severity with the progression of AF. This was also supported by less progression of AF after dopaminergic therapy. Another study did not find any association of PLMS with ventricular or atrial arrhythmias. ${ }^{50}$

\section{RLS/PLMS and echocardiographic studies, heart failure, and heart transplant}

Recent studies have explored the possibility of structural and functional heart changes in RLS/PLMS patients. In addition, previous studies have associated RLS/PLMS with CHF. The evidence of echocardiographic studies, CHF, heart transplant, and its association with RLS/PLMS are discussed here.

Giannaki et $\mathrm{al}^{54}$ analyzed 19 RLS patients receiving hemodialysis. The patients were subclassified into RLS with PLMS (N=10; PLMI 66.5 $\pm 27.0 / \mathrm{h}$ ) and RLS without PLMS $(\mathrm{N}=9$; PLMI 10.6 $\pm 7.4 / \mathrm{h})$ and were assessed for left ventricular hypertrophy (LVH) and left ventricular diastolic function, as measured by M-mode echocardiography, and conventional Doppler/tissue Doppler, respectively. The PLMS group had an increased left ventricle (LV) internal diameter $(P=0.007)$ and increased LV mass ( $202 \pm 52$ vs $150 \pm 37 \mathrm{~g}, P=0.026)$. Diastolic function indices were not different between the groups. Their findings suggest an association between severe PLMS with further LV structure abnormalities in hemodialysis (HD) patients with RLS. Of note, the group without PLMS had a higher severity of RLS as per the International Restless Legs Scale (IRLS) score compared with the group with PLMS (22.2 \pm 10.2 vs $14.6 \pm 10.9 ; P=0.157)$, and we can speculate that the effects of RLS/PLMS disorders on cardiac structure are due to the severity of PLMS and not of RLS. However, this conclusion cannot be made as this difference was not statistically significant $(P=0.157) .{ }^{54}$ Mirza et al retrospectively analyzed 584 RLS patients and further subclassified them into frequent $(>35 / \mathrm{h})$ and infrequent $(\leq 35 / \mathrm{h})$ PLMI groups. The group with PLMI $>35 / \mathrm{h}$ had significantly higher $\mathrm{LVH}$ than the group with PLMI $<35 / \mathrm{h}$, even after multivariate analysis $(\mathrm{OR}=2.45 ; 95 \% \mathrm{CI}, 1.67-3.59 ; P<0.001)$. Rates of heart failure and mortality were also higher at follow-up in the RLS group with PLMI $>35 / \mathrm{h}$. The ejection fraction (EF) was not different between the groups. ${ }^{6}$ A study of 23 men with severe, stable CHF (all with $\mathrm{EF}<35 \%$ ) and 9 healthy controls found that $52 \%$ of CHF patients have a PLMI $>25 / \mathrm{h}$. Of those, one-third had a PLMI $>50 / h$, compared with control 
subjects (11\%). ${ }^{55}$ In another study Javaheri ${ }^{56}$ included 100 patients with heart failure. Of those, 55 had recordings of anterior tibialis electromyogram on polysomnography. Twenty percent of these patients had a PLMI $>5 / \mathrm{h}$, with an average index of $35 / \mathrm{h}$. The AHI were comparable between the groups. ${ }^{56}$ Limitations of the study include small sample size and lack of a control group. In addition, a PLMI up to $15 / \mathrm{h}$ is not uncommon in the general population. ${ }^{45}$ Skomro et al prospectively studied 79 subjects (mean age 59 years; 29 women) with stable CHF and found a prevalence of PLMI $>5 / \mathrm{h}$ in $19 \%$ of patients. The AHI was not different between the groups. ${ }^{57}$ The previous 2 studies (Javaheri and Skomro et al) showed a similar prevalence of PLMI in $\sim 20 \%$ in the CHF population.

There are a few case reports and case series addressing heart transplant and PLMS associations. Hanly and Zuberi published a case of a 46-year-old male who developed insomnia after a large myocardial infarction, with subsequent development of CHF and Cheyne-Stokes respirations. Polysomnography showed a PLMI of $158 / \mathrm{h}$, and one third of the PLMS were associated with arousals. After heart transplantation, his PLMI decreased to $12 / \mathrm{h}$. His other sleep disorders including insomnia and Cheyne-Stokes breathing also improved after transplant. ${ }^{58}$

A cross-sectional study of 45 cardiac transplant recipients in the Veterans Affairs Medical Center found the prevalence of PLMS to be $33 \%$ (defined as a PLMI $\geq 15 / \mathrm{h}$; average PLMI $55 \pm 43 / \mathrm{h}$ ). Forty-five percent of those PLMS patients had coincident RLS, but only in 2 patients OSA and PLMS were coincident, indicating that PLMS was not due to the higher prevalence of OSA. ${ }^{59}$ A more recent study included 143 solid organ transplant recipients (kidney, liver, heart, lung, or pancreas). Of the 13 heart transplant recipients in this study, none was classified as having RLS. ${ }^{60}$ The prevalence of selfreported RLS in this study was lower than other reports of RLS in transplant recipients, especially in kidney transplant recipients $(2.6 \%$ in this study vs $4.8 \%){ }^{61}$

In summary, the prevalence of PLMI in CHF ranges from $19 \%$ to $52 \%$. However, the studies used different definitions for the classification of significant PLMI (from $>5 / \mathrm{h}$ to $>35 / \mathrm{h}$ ), thus making comparisons difficult between studies. In general, most sleep clinicians will consider PLMI $>15 / h$ as abnormal in adults, as PLMI from 5 to $15 / \mathrm{h}$ is common in the general population. ${ }^{45}$ Overall, limited studies show a positive association between CHF and RLS/PLMS. In terms of heart transplant and RLS/PLMS, studies are even more limited. One study and a case report showed an association between PLMS and heart transplant, and another study of self-reported RLS did not.

\section{Association between RLS/PLMS and autonomic nervous system (ANS) alteration}

Whether PLMS cause or are the result of instability of the ANS is not established. PLMS can be associated with arousals, and some authors have proposed that a hyperarousal state or sleep disruption may lead to alteration of the ANS. This section focuses on the alteration of the heart rate, BP, and the presence of non-dipping BP in relation to PLMS.

Pennestri et a ${ }^{30}$ evaluated the heart rate and $\mathrm{BP}$ changes between PLMS with and without arousal in 10 subjects with primary RLS (mean age 47.3 years; 4 women). They used overnight polysomnogram and noninvasive beat-to-beat BP monitoring. Significant BP elevations coincident with PLMS were found, with an average of SBP of $22 \mathrm{mmHg}$ and DBP of $11 \mathrm{mmHg}$ over baseline. PLMS-microarousals showed a significantly greater BP elevation compared with PLMS without microarousals $(7 \mathrm{mmHg}$ greater for the SBP and $\sim 3.6$ $\mathrm{mmHg}$ greater for the DBP). Although PLM during wakefulness also showed an increase in BP, the magnitude was not as large as that during sleep. Also, increase in pulse rate was noted in both the subgroups..$^{30} \mathrm{~A}$ study of 8 RLS patients measured autonomic activation during changes in BP and pulse rate that occur with PLMS. "Fake PLMS" (voluntary movements mimicking PLMS prior to bedtime) were used as controls. The magnitude of the mean SBP elevation by PLMS (from the highest to the lowest) was as follows: respiratoryrelated limb movements (18.9 $\mathrm{mmHg}$ above baseline) was greater than PLMS with microarousals $(16.7 \mathrm{mmHg}$ above baseline), PLMS without microarousal (11.2 $\mathrm{mmHg}$ above baseline) was greater than periodic limb movements while awake (11.7 mmHg above baseline). Fake PLMS (controls) showed a mean of SBP elevation of $3.2 \mathrm{mmHg}$. There was no evidence for sleep apnea in the subjects of this study. ${ }^{31}$ Erden et al included 230 treatment naive hypertension patients to explore the association between RLS and night-time BP patterns. There was a high prevalence of RLS (28.5\%) in this study. The prevalence of RLS in patients with hypertension was more than twice compared with normotensive patients ( 35.3 vs $17.2 \%$, respectively; $P<0.01$ ). In both hypertensive and normotensive patients, RLS was more prevalent in the nondipping compared with dipping patients ( 34.7 vs $21.2 \%$, respectively; $P=0.028$ ). In logistic regression analysis, RLS was found to be an independent factor for the nondipping BP patterns $(\mathrm{OR}=1.96 ; 95 \% \mathrm{CI}, 1.05-3.67 ; P=0.035) .{ }^{32} \mathrm{This}$ BP pattern has been shown to be an independent predictor of cardiovascular risk. ${ }^{32}$ Izzi et al studied the cardiovascular autonomic function of 12 RLS patients and 14 controls in terms of cardiovascular reflexes and heart rate variability 
(HRV) during wakefulness. They used different testing such as head-up tilt test (HUTT), deep breathing, Valsalva maneuver, hand grip, and cold face. Compared to controls, RLS showed a significant increase in SBP in supine rest, and a trend but not significant lower ratio of Valsalva value. In addition, the RLS group did not present the physiological HRV and HUTT changes found in control subjects. The authors concluded that RLS patients have a tendency toward hypertension, reduced sympathetic and parasympathetic responses at HUTT, and decreased parasympathetic drive to BP changes..$^{33} \mathrm{~A}$ prospective, single-blind, placebo-controlled study included 23 RLS patients and 10 controls to analyze HRV changes during PLMS and in sleep stage 2 independent of PLMS. The study also evaluated the treatment response in HRV with pramipexole and placebo within the RLS group. Basal sympathovagal balance (stable sleep stages without PLMS) were not different between RLS patients and controls, and neither between RLS subjects before and after pramipexole treatment. In the RLS group, the PLMS-related heart rate changes were higher than control. In addition to reduced PLMS in the RLS group, pramipexole decreased the heart rate increases during PLMS to levels comparable to controls. These results point to a higher autonomic phasic activation during PLMS in RLS patients, but not abnormal baseline sympathovagal balance in stable sleep. ${ }^{62} \mathrm{~A}$ subsequent study by Palma et $\mathrm{al}^{63}$ showed similar results. This study compared the basal HRV in 13 patients with PLMS $(\geq 20 / \mathrm{h})$ and 13 matched controls. In contrast with other studies, the authors method involved the analysis of the HRV in "stable sleep," that is, they excluded epochs with arousals as well as periods of 30 seconds before and after the leg movements. They hypothesized that if basal cardiac autonomic tone is not abnormal during "stable sleep," it is unlikely that a tonic dysfunction of the autonomic system is related to the PLMS pathogenesis. Both the groups showed a similar basal cardiac autonomic modulation during "stable sleep." ${ }^{63}$ The last 2 studies argued against a relationship for a basal disturbance of the cardiac ANS in the pathogenesis of PLMS. ${ }^{62,63}$

A recent double-blind, placebo-controlled trial included 81 patients with moderate to severe RLS with the aim to investigate the effect of the rotigotine patch on PLM-associated nocturnal SBP elevations. RLS patients were randomized to 1 of 2 groups: rotigotine $1-3 \mathrm{mg} / 24 \mathrm{~h}$, or placebo. Rotigotine significantly reduced the PLM-associated SBP elevations compared with placebo $(P<0.0001)$. In addition, total SBP and total DBP were also significantly reduced in the rotigotine group. This study provided class I evidence for the reduction of PLM-associated nocturnal BP in patients with moderate to severe RLS. ${ }^{7}$ A study of 20 RLS patients free of cardiovascular comorbidities and 20 matched controls found lower baroreflex gain $(P=0.04)$, lower leg blood flow $(P<0.001)$, and greater leg vascular resistance $(P<0.0001)$ in RLS patients. As other indices of cardiovagal control (respiratory sinus arrhythmia and Valsalva ratio) did not vary by RLS status, the authors hypothesized that autonomic alterations in RLS are specific to baroreflex and vascular resistance, but not to cardiovascular autonomic control more generally. These changes could potentially be due to heightened sympathetic outflow in RLS. ${ }^{34}$

In summary, multiple studies but not all have shown association of PLMS with alterations in autonomic activity. Recently, well-designed studies have expanded the investigation in this topic by testing dopaminergic medications in PLMS. ${ }^{7,62}$ The results are promising, showing evidence of improvement in autonomic alterations related to PLMS. Finally, some studies argued against an abnormality in RLS patients of the baseline (tonic) sympathovagal balance during the sleep free of PLMS, but an abnormal increase in autonomic phasic activation when the PLMS occur. Further studies in this topic are granted.

\section{Association between RLS/PLMS and stroke}

There is recent evidence linking RLS/PLMS and stroke. Studies of RLS/PLMS and associated stroke range from case reports to epidemiological studies and to randomized clinical trials. It has been found that there is association of RLS not just with ischemic stroke but also with small vessel disease (SVD), hemorrhagic strokes, as well as subarachnoid hemorrhages. The association between RLS/PLMS and stroke is revised here. Studies in this section are summarized in Table S1 (case reports are not included).

\section{Case reports of RLS/PLMS after acute stroke}

There are multiple case reports of acute stroke with either concomitant RLS symptoms or development of RLS/PLMS in the post-stroke period. In most cases, these infarctions are localized in the basal ganglia or pons, and symptoms respond well to dopaminergic therapy. In addition, symptoms are typically contralateral to the infarction, and in a few cases bilaterally, but usually predominant in the contralateral limb. ${ }^{64-67}$

\section{RLS and stroke}

In a study of 1986 men (age 55-59 years) included in the Caerphilly cohort in the UK, participants were followed up for the next 10 years, and those who answered positive for 
RLS had small but significantly higher incidence of stroke (aOR $=1.67 ; 95 \% \mathrm{CI}, 1.07-2.60 ; P=0.024)$. This study was limited by not using the IRLSSG criteria and not excluding RLS mimics. ${ }^{26}$ In the same way, a larger observational study of 7392 US Veterans with a median follow-up of 8.1 years found incident RLS to be associated with incident stroke (HR $=3.89$; CI 95\% 3.07-4.94) as compared with a propensitymatched cohort. ${ }^{23}$ Winter et al reported contradictory results in 2 different studies. One study showed an association of RLS with stroke in male physicians $(\mathrm{N}=22,786$, aOR $=1.40$; 95\%CI, 1.05-1.86) after multivariable adjustments ${ }^{3}$ but not in the counterpart study of female health professionals $(\mathrm{N}=30,262){ }^{4}$

A prospective study by Schuiling et $\mathrm{al}^{68}$ included 83 post-subarachnoid hemorrhage survivors at 1 or more year after hemorrhage. Twenty of 28 patients who reported severe sleep disturbances underwent 48-hour polysomnography at home. RLS/periodic limb movement disorder (PLMD) was found in $25 \%$ of the patients (RLS/PLMD based on a PLMI $>10 /$ h plus a history of RLS). This study was limited by a small sample and the absence of a control group. ${ }^{68}$ Another prospective study of 137 patients with ischemic stroke free of RLS at baseline showed an RLS incidence of $12.4 \%$. One of 17 stroke-related RLS patients had a cortical stroke, the other 16 had subcortical strokes. Ten of the strokes were located in the basal ganglia/corona radiata, 4 in the pons, and 3 in other areas, with 12 out of 17 patients having bilateral symptoms. ${ }^{69}$ The findings of the study led the authors to think that the pyramidal tract or the basal ganglia-brainstem axis areas (which are also involved in sleep-wake cycles and motor functions) may lead to RLS after an ischemic stroke. Similar results were found by Gupta et $\mathrm{al}^{70}$ where $80 \%$ of the strokes in the RLS patients were subcortical in nature (16 hemorrhagic and 13 ischemic stroke). In this study ( $\mathrm{N}=346$, RLS prevalence of $10.1 \%$ ), RLS symptoms were present on average $60 \pm 40$ months before stroke. ${ }^{70}$ Worth mentioning, the prevalence of RLS in the prior 2 studies are in the range of the general population $(3.9 \%-14.3 \%) .{ }^{13} \mathrm{~A}$ different work by Medeiros et $\mathrm{al}^{71}$ longitudinally analyzed the outcomes at 3 and 12 months post-stroke in patients with RLS $(\mathrm{N}=12)$ and without RLS (N=51). After adjustment for diabetes and body mass index (BMI), the RLS group had significantly worse post-stroke outcomes than those without RLS. However, RLS patients had more severe stroke by the Barthel Index and modified Rankin Scale at baseline, and worse outcomes are expected accordingly with higher stroke severity. ${ }^{71}$ In addition, the sample in this study was small.

More recently, a few studies involving magnetic resonance imaging (MRI) and carotid ultrasound have been published.
In a study involving MRI scans, Walters et $\mathrm{al}^{72}$ compared 26 RLS cases and 241 controls. Although the results did not achieve statistical significance, RLS subjects showed increased prevalence of cerebrovascular events of all type, cortical atrophy, and higher volume of subcortical lesions. ${ }^{72}$ Later, another prospectively study analyzed RLS patients and controls ( $\mathrm{n}=171)$ with brain MRI. Patients with RLS duration of $>10$ years had an SVD area and volume significantly higher compared with both controls and RLS $<10$ years of duration. Importantly, in this study, the age, duration of RLS symptoms, and the interaction of RLS duration and age were independent predictors for the cumulative cerebral SVD. ${ }^{8}$ Finally, a study evaluated carotid intima-media thickness (IMT) with high-resolution B-mode ultrasound in 38 idiopathic RLS (iRLS) and 64 controls and found significantly lower mean IMT $(P<0.05)$ in iRLS patients. The authors concluded that iRLS patients may have a lower risk progression of atherosclerosis. However, this study was limited by a small sample and wide age distribution $(59.00 \pm 16.18$ years for iRLS vs $58.94 \pm 12.85$ years for controls). Furthermore, patients with RLS and PLMS, and isolated PLMS were excluded from this study, possibly contributing to a more "pure" iRLS sample and less atherosclerosis. ${ }^{73}$

In summary, the evidence supports that different types of stroke (ischemic, hemorrhagic, and subarachnoid hemorrhage [SAH]) can cause RLS, especially subcortical strokes in the basal ganglia and pons. Although the evidence supporting RLS as a risk factor for stroke is not definitive at this moment, a recent study found RLS symptoms duration to be an independent predictor for the cumulative cerebral SVD. ${ }^{8}$ However, data from carotid studies showing less atherosclerosis in iRLS patients contrast with this study. Further studies are needed to clarify the unfilled gaps.

\section{PLMS and stroke}

There are also studies evaluating the association between PLMS and stroke. In a prospective study, Benbir et al ${ }^{74}$ analyzed 35 consecutive patients with acute stroke (ischemic supratentorial) and 35 age- and gender-matched controls In the stroke arm, 77\% had PLMI $>5 / \mathrm{h}$ and $54.3 \%$ had a PLMI $>15 / h$. In the control group, $28.5 \%$ had PLMI $>5 / \mathrm{h}$ and $17.1 \%$ had PLMI $>15 / \mathrm{h}$. These differences were statistically significant $(P<0.05)$ with most patients presenting PLMS contralateral to the stroke. ${ }^{74}$ A retrospective study (40 stroke patients and 40 matched controls) by Coelho et $\mathrm{al}^{75}$ found that $47 \%$ of stroke patients showed PLMS $>5 / \mathrm{h}$ compared with $12.5 \%$ in the control group $(P<0.001)$. However, the retrospective design of this study precludes the establishment of causality. In addition, the onset of PLMS in relation to stroke 
was missing, and no details were offered about the location of the strokes to make further conclusions. ${ }^{75}$

In conclusion, multiple studies have shown increased prevalence of PLMS in patients with stroke. As PLMS developed rapidly after acute stroke in most cases, it seems that they are a consequence of stroke. In addition, although sleep apnea and insomnia are known risk factors for cardiovascular/ cerebrovascular disease, multiple studies showed an association between RLS/PLMS and stroke even after adjustments for sleep apnea and insomnia. ${ }^{8,23}$ PLMS may also be a risk factor for stroke, but more prospective and well-designed studies are needed to make a definitive conclusion.

\section{Association between RLS/PLMS and other cardiovascular risk factors Obesity, increased BMI, and diabetes}

Various studies have shown an association of RLS with obesity/ increased BMI and diabetes, known risk factors for CVD. $3,4,25,40$ However, other studies could not demonstrate such an association, especially after adjusting for confounders. ${ }^{24,41,43,76,77}$ Inconsistent results may be due to the variable study designs (a few prospective and most cross-sectional/epidemiological studies), the criteria used to diagnose RLS, and that most studies failed to address RLS severity and duration.

\section{Hypoxia and impaired microcirculation}

Some studies have been conducted to assess other mechanisms that may be associated with RLS/PLMS, including hypoxia, microcirculation abnormalities, oxidative stress (OS), and inflammation. These states, independently or linked to each other, have been associated with increased risk of CVD in other sleep disorders such as sleep apnea. ${ }^{78-81}$

A large-scale study to identify genes related to RLS showed association of variants in the NOS1 gene in RLS patients. ${ }^{82}$ NOS1 gene encodes the protein nitric oxide synthase (NOS), which synthesizes nitric oxide (NO) from 1-arginine, a molecule involved in vasodilation, antiinflammatory and antithrombotic properties, neurotransmission, among other biological processes. ${ }^{83}$ Thus, variations in the gene will lead to variations in NOS, and thus variations in NO activity. This study supports the involvement of the $\mathrm{NO}$ /arginine pathway in the pathogenesis of RLS. ${ }^{82}$

Intermittent hypoxia and hypoxia response pathways (cell survival pathways) have been suggested as a possible mechanism in the pathogenesis of RLS, ${ }^{84}$ and thus increased risk of CVDs. An important survival pathway is the hypoxiainducible factor-1 (HIF-1). In hypoxia HIF-1 $\alpha$, a subunit of HIF-1 involved in pro-oxidant activities, becomes stable and dimerizes. In this form, it acts as a transcription factor and regulates the expression of multiple proteins, including transferrin receptor, transferrin, vascular endothelial growth factor, endothelin, and erythropoietin, ${ }^{84-86}$ factors that have been found to be altered in RLS.

A post-mortem study of 6 RLS patients versus 6 controls by Patton et $\mathrm{al}^{84}$ measured proteins in the substantia nigra, and brain microvasculature was expected to be involved in the HIF-1 $\alpha$ pathway. Their results support the hypothesis that HIF-1 $\alpha$ pathway is activated in multiple cell types in RLS. Furthermore, the increase in neuronal nitric oxide synthase (nNOS) and nitrotyrosine suggests that nitric oxide is involved in the activation of these pathways. ${ }^{84}$ Anderson et al demonstrated impaired microcirculation using laserDoppler flowmetry and whole-body thermography in RLS patients. ${ }^{87}$ Salminen et al found a correlation of worse peripheral hypoxemia with RLS severity, and reversal of hypoxemia with pramipexole treatment, supporting the hypothesis that peripheral vascular systems are involved in RLS pathophysiology. ${ }^{88}$ However, a subsequent study could not confirm the hypothesis of impaired microcirculation in RLS patients. The authors postulated that findings in prior studies of altered blood flow and microcirculation may be related to a dopaminergic treatment effect, rather than RLS. ${ }^{89}$ Finally, a study using ultrasound measurements of brachial artery flow-mediated dilatation found poorer vascular endothelial function in RLS patients compared with controls, supporting the involvement of the peripheral vascular system in RLS generation. ${ }^{90}$

In summary, the above lines of evidence support the involvement of hypoxic pathways and peripheral vascular system involvement in RLS pathophysiology, mechanisms that have been associated with increased risk of CVD.

\section{Inflammation and oxidative stress markers}

Trotti et $\mathrm{al}^{91}$ evaluated systemic inflammation and PLMS in 137 RLS patients. RLS patients with $\geq 45$ PLMS/h had more than 3-fold the odds of elevated C-reactive protein than those with fewer PLMS. TNF-alpha and interleukin (IL)-6 were not different between the groups. Limitations of this study include lack of a control group and the retrospective nature of the study. ${ }^{91}$ Weinstock et al found that inflammatory bowel syndrome and small intestinal bacterial overgrowth were more common in RLS patients than in the control group. They hypothesized that RLS patients are relatively immunocompromised and that autoimmune changes may lead to auto-antibodies and inflammation, subsequently 
causing iron deficiency leading to RLS. ${ }^{92}$ A genetic prospective longitudinal study of 316 HIV-positive adults found that carrying two copies of the minor allele for IL-1B or carrying the minor allele for IL-17A was associated with RLS. ${ }^{93} \mathrm{~A}$ study to identify markers of OS included 50 RLS patients and another 50 gender- and age-matched healthy controls and measured many individual, and combinations of, oxidant and antioxidant molecules. Study findings suggest efforts in the body toward the protection of dopaminergic activity in the CNS from OS. The findings support the theory of increased OS markers, as well as increased anti-OS activity in RLS patients, adding support to the dopaminergic dysfunction in this condition. ${ }^{94}$ Other OS markers were comparable between the groups. Finally, another study found increased oxidation protein products (malondialdehyde levels) and decreased thiol and nitric oxide levels in RLS patients, suggesting possible increased OS in this condition. ${ }^{95}$

\section{Association between RLS/PLMS and mortality}

Multiple epidemiological/cross-sectional but also prospective studies have reported increased mortality in RLS patients and in those with increased PLMI. ${ }^{6,23,96,97}$ However, a large study did not find association with RLS and mortality, ${ }^{98}$ and some studies showed increased mortality in females but not in males. ${ }^{99,100}$ Studies of mortality and RLS/ PLMS have been limited by a small number of patients, epidemiological/cross-sectional designs, short follow-up period, and different definitions to classify RLS/PLMS patients. In general, the limited evidence available suggests an association between RLS/PLMS and increased mortality in this population.

\section{Secondary RLS/PLMS and risk of cardiovascular disease}

As stated previously, RLS can be classified as primary (idiopathic) or secondary when it is associated with pregnancy, IDA, and chronic renal failure. ${ }^{2}$ Other reported conditions where RLS occurs more frequently include narcolepsy, OSA, PD, MS, rheumatoid arthritis, and other conditions. ${ }^{2,9}$

CKD and end-stage renal disease (ESRD) are well known to be associated with CVD. The prevalence of RLS in ESRD varies greatly according to different studies and regions. For example, some studies report a prevalence of $12 \%-25 \% .^{101-103}$ Other studies in CKD patients (but not on dialysis) report a similar prevalence of $10 \%-30 \%$ regardless of CKD stage, ${ }^{104-107}$ whereas in renal failure clinics in USA and Europe, it fluctuates from $11 \%$ to $58 \% .^{9}$ In addition, PLMS may affect $\sim 50 \%-70 \%$ of patients with ESRD. ${ }^{108,109}$
There are studies reporting a higher incidence of CVD in renal patients with RLS/PLMS. Araujo et al in a crosssectional study of 400 ESRD patients receiving hemodialysis found an association of hypertension with moderate to severe RLS versus no-RLS after controlling for OSA risk $(P=0.02) .{ }^{101} \mathrm{~A}$ prospective study of $100 \mathrm{ESRD}$ patients in hemodialysis ( 31 with and 69 without RLS) found that those with RLS had increased prevalence for new cardiovascular events compared with the group without RLS (64.5\% vs $39.1 \%$, respectively; $P=0.019$ ). In this study, cardiovascular events were myocardial infarctions, cerebral stroke, or peripheral artery occlusion. Of note, cardiovascular events and mortality increased with severity of RLS in this study. ${ }^{110}$ Similarly, a big prospective study of 1092 ESRD subjects from 17 hemodialysis centers in Taiwan, with mean follow-up period of 3.7 years, showed more hypertension, cardiovascular $(\mathrm{aHR}=2.82,95 \% \mathrm{CI} 2.02-4.11)$, and cerebrovascular events $(\mathrm{aHR}=2.41,95 \% \mathrm{CI} 1.55-3.75)$ in the RLS group versus the non-RLS group. ${ }^{111}$

Besides RLS, PLMS is also claimed to increase the risk of CVD in renal patients. In a study of kidney-transplanted patients and waiting-list subjects, Lindner et $\mathrm{al}^{112}$ found that subjects with severe PLMS in either group, defined as PLMI $>25 / \mathrm{h}$, showed increased 10-year risk of coronary heart disease (by Framingham Score) compared with less severe PLMI (transplanted patients $18 \%$ vs $7 \%, P=0.002$; waiting-list subjects $10 \%$ vs $4 \%, P=0.032$ ). In the transplant group, severe PLMS also showed an increased 10-year risk of stroke ( $P=0.002)$. The cross-sectional design of this study precludes any directional or causal conclusions. ${ }^{112}$ In another single hemodialysis center study, ESRD with PLMS (defined as PLMI $\geq 15 / h$ ) showed an increased risk of cardiovascular events $(P=0.010)$ and mortality $(P=0.008)$. Interestingly, the AHI and the oxygen desaturation index were not associated with mortality in this study, but the sample was small. ${ }^{113}$ Finally, a small cross-sectional study of hemodialysis patients with RLS compared subjects with PLMS (N=10) versus nonPLMS (N=9). The PLMS group showed increased LV diameter ( $4.96 \pm 0.61$ vs $4.19 \pm 0.48 \mathrm{~cm}, P=0.007$ ) and increased LV mass $(202 \pm 52$ vs $150 \pm 37 \mathrm{~g}, P=0.026)$ compared with the nonPLMS. In this study, PLMS was defined as PLMI $>25 / \mathrm{h}^{54}$

Taking a brief look at mortality, multiple studies have shown increased mortality in ESRD patients with RLS. ${ }^{110,114,115}$ Benz et al found PLMS severity to correlate with high mortality in this population. ${ }^{116}$ However, a recent study could not confirm an increased mortality in ESRD patients with RLS at 3-year follow-up $(\mathrm{N}=549) .{ }^{117}$ Thus, the association between mortality and RLS/PLMS is not definitive at this time, reinforcing the need for further studies. 
Other conditions in which RLS has been reported to occur more frequently than the general population include IDA, MS, PD, pregnancy, and others. No studies that directly addressed CVD, stroke, hypertension, or mortality were found in RLS comorbid with IDA or MS. However, we found a few studies in PD with possible associated CVD in terms of hypertension. In one study of newly diagnosed PD patients ( $\mathrm{N}=225$, RLS prevalence of $16 \%$ ), those with RLS had more nocturnal and supine hypertension compared with PD patients without RLS. ${ }^{118}$ Another study of PD patients versus controls (both with similar PLMI of $\sim 13 / \mathrm{h}$ ) found reduced heart rate responses to leg movements in PD patients. ${ }^{119}$ Autonomic dysfunction is a well-known non-motor manifestation in PD and may confound the study results. Due to the paucity of studies and possible confounders related to $\mathrm{PD}$, no conclusions can be made at this time in terms of the association of RLS with CVD in this population. Studies in pregnancy were not included in this manuscript.

Despite incongruences, the above data suggest in general an association of secondary RLS/PLMS (especially in renal disease) with increased risk of cardiovascular conditions and possible increased mortality too. The pathophysiology conferring higher cardiovascular risk in RLS/PLMS remains unknown, but it is possible that reported increased sympathetic activity in RLS/PLMS can lead to nocturnal hypertension/non-dipping phenotype, total hypertension, and higher cardiovascular events and mortality.

\section{Discussion}

\section{Perspectives of RLS/PLMS and cardiovascular disease}

The evidence for the mechanism that confers increased risk of CVD in patients with RLS/PLMS is emerging. Hypertension is a well-known risk factor for CVD. The available data on RLS/PLMS is most consistent with increased daytime BP in sufferers of the condition. In the same line, multiple studies, but not all, have associated RLS/PLMS with sympathetic hyperactivity. ${ }^{7,30-33}$ Increased sympathetic activity can lead to alterations in heart rate and nocturnal hypertension/nondipping phenotype. Moreover, other studies have shown that nocturnal non-dipping by itself is associated with increased cardiac structural alterations, ${ }^{120}$ more cardiovascular events, ${ }^{121}$ and confers increased risk for the development of CVD. ${ }^{122,123}$ Thus, by causing hypertension (and nocturnal non-dipping), RLS/PLMS may lead to CVD.

In the scenario where RLS/PLMS patients are not found with hypertension, it is possible that transient increases in BP associated with PLMS can cause endothelial vascular damage. This may eventually lead to arteriosclerosis. In addition, increased transient elevations in BP during PLMS can cause rupture or ulceration of a stable cholesterol plaque, leading to acute cardiovascular events.

Less clearly, some studies have shown increased arrhythmias in patients with RLS/PLMS. Patients with PLMS can have sleep alterations with frequent arousals and fragmented sleep, thus again leading to increased sympathetic activity. These alterations may set the conditions for increased heart arrhythmias, which can lead to unstable hemodynamics and tissue hypoperfusion, with consequent ischemia, OS, and eventually CVD. Alternatively, arrhythmias (especially AF) can cause embolic events such as stroke.

More clearly, there is evidence that supports that RLS/ PLMS can emerge as a consequence of subcortical stroke. However, RLS/PLMS as a risk factor for stroke is less definitive. Besides above possible mechanisms for the development of CVD (and thus stroke), a small study used near-infrared spectroscopy and documented transient cerebral hemodynamic fluctuations with consequent hypoxia accompanying PLMS. ${ }^{124}$ Theoretically, these metabolic alterations could lead to small cerebral arteriole damage and subsequent SVD, ${ }^{8}$ which is a known risk factor for stroke.

Finally, there is limited evidence associating peripheral hypoxia, altered microcirculation, OS, and inflammation with RLS/PLMS; states that have been associated with increased risk of CVD. Similarly, these alterations may cause endothelial dysfunction and vascular damage, later leading to clinical CVD events. ${ }^{84,90,125,126}$ Although the mechanism of hypoxia is not known in RLS/PLMS, proposed hypotheses include altered microcirculation/reduced blood flow, or altered iron metabolism compromising oxygen uptake to peripheral tissues. However, more data are needed to evaluate these possibilities.

\section{Conclusion}

RLS is a sensorimotor neurological disease which has been associated with increased CVD. In general, the majority of the studies support a positive association between RLS and heart disease/CVD. Although most studies are cross-sectional in nature, there are some prospective studies adding support to these associations. As most studies are epidemiologic crosssectional studies, causality cannot be definitely established. In addition, the heterogenicity of the results may be due to the different study designs, studies including both genders vs only one gender, and the different criteria used to define RLS. Other factors may include a diagnosis of RLS based only on questionnaires; lack of exclusion of RLS mimics; lack of consideration for symptoms duration or severity, variable follow-up periods in different studies. Future studies should 
focus on longitudinal studies with strict use of the newest IRLSSG criteria, excluding RLS mimics in a face-to-face interview performed by sleep experts, addressing RLS severity and duration, and longer follow-up time studies. Finally, as a few studies with the capacity to discern between primary/ iRLS versus secondary RLS suggest less CVD association in the first group, studies comparing primary versus secondary RLS should also be considered to clarify if such an association is inherent to secondary RLS only, or both subtypes of RLS. ${ }^{2,73}$ There is increasing evidence suggesting the link between RLS/PLMS and CVD. However, the increased risk for CVD in RLS/PLMS patients is not definitive at this time. A referral to the appropriate specialist should be considered when cardiovascular risks are identified. Further studies are needed to definitively determine whether there is a casual association of RLS/PLMS with CVD.

\section{Disclosure}

This was not an industry-sponsored study. Dr Vargas-Pérez has indicated no financial conflicts of interest. Dr Bagai has received grant money from Xenoport and UCB Pharma for studies on RLS. Dr Walters has received grant money from Xenoport, UCB Pharma, and MundiPharma for studies on RLS, and has served on the RLS medical advisory board for Xenoport and UCB Pharma. The authors report no other conflicts of interest in this work.

\section{References}

1. Mozaffarian D, Benjamin EJ, Go AS, et al. Heart disease and stroke statistics-2016 update: a report from the American Heart Association Statistics Committee and Stroke Statistics Subcommittee. Circulation. 2016;133:e38-360.

2. Van Den Eeden SK, Albers KB, Davidson JE, et al. Risk of cardiovascular disease associated with a restless legs syndrome diagnosis in a retrospective cohort study from Kaiser Permanente Northern California. Sleep. 2015;38(7):1009-1015

3. Winter AC, Berger K, Glynn RJ, et al. Vascular risk factors, cardiovascular disease, and restless legs syndrome in men. Am J Med. 2013;126(3):228-325.

4. Winter AC, Schürks M, Glynn RJ, et al. Vascular risk factors, cardiovascular disease, and restless legs syndrome in women. Am J Med. 2013;126(3):220-227.

5. Koo BB, Blackwell T, Ancoli-Israel S, Stone KL, Stefanick ML, Redline S. Osteoporotic Fractures in Men (MrOS) Study Group. Association of incident cardiovascular disease with periodic limb movements during sleep in older men: outcomes of sleep disorders in older men (MrOS) study. Circulation. 2011;124(11):1223-1231.

6. Mirza M, Shen WK, Sofi A, et al. Frequent periodic leg movement during sleep is associated with left ventricular hypertrophy and adverse cardiovascular outcomes. JAm Soc Echocardiogr. 2013;26(7):783-790.

7. Bauer A, Cassel W, Benes H et al. Rotigotine's effect on PLMassociated blood pressure elevations in restless legs syndrome: an RCT. Neurology. 2016;86(19):1785-1793.

8. Ferri R, Cosentino FI, Moussouttas M, et al. Silent cerebral small vessel disease in restless legs syndrome. Sleep. 2016;39(7):1371-1377.

9. American Academy of Sleep Medicine. International Classification of Sleep Disorders. $3^{\text {rd }}$ ed. Darien (IL): AASM; 2014.
10. Walters AS. Toward a better definition of the restless legs syndrome. The International Restless Legs Syndrome Study Group. Mov Disord. 1995;10(5):634-642.

11. Allen RP, Picchetti DL, Garcia-Borreguero DG, et al.; for IRLSSG. Restless legs syndrome/Willis-Ekbom disease diagnostic criteria: updated International Restless Legs Syndrome Study Group (IRLSSG) consensus criteria - history, rationale, description, and significance. Sleep Med. 2014;15(8):860-873.

12. Hening W, Walters AS, Allen RP, Montplaisir J, Myers A, Ferini-Strambi L. Impact, diagnosis and treatment of restless legs syndrome (RLS) in a primary care population: the REST (RLS epidemiology, symptoms, and treatment) primary care study. Sleep Med. 2004;5(3):237-246.

13. Ohayon MM, O’Hara R, Vitiello MV. Epidemiology of restless legs syndrome: a synthesis of the literature. Sleep Med Rev. 2012;16(4):283-295.

14. Allen RP, Bharmal M, Calloway M. Prevalence and disease burden of primary restless legs syndrome: results of a general population survey in the United States. Mov Disord. 2011;26(1):114-120.

15. Montplaisir J, Boucher S, Poirier G, Lavigne G, Lapierre O, Lespérance P. Clinical, polysomnographic, and genetic characteristics of restless legs syndrome: a study of 133 patients diagnosed with new standard criteria. Mov Disord. 1997;12(1):61-65.

16. Berry RB, Brooks R, Gamaldo CE, et al.; for the American Academy of Sleep Medicine. The AASM Manual for the Scoring of Sleep and Associated Events: Rules, Terminology and Technical Specifications, Version 2.2 (www.aasmnet.org). Darien (IL): American Academy of Sleep Medicine; 2015.

17. Polydefkis M, Allen RP, Hauer P, Earley CJ, Griffin JW, McArthur JC. Subclinical sensory neuropathy in late-onset restless legs syndrome. Neurology. 2000;55(8):1115-1121.

18. Earley CJ, Connor J, Garcia-Borreguero D, et al. Altered brain iron homeostasis and dopaminergic function in restless legs syndrome (Willis-Ekbom disease). Sleep Med. 2014;15(11):1288-1301.

19. Ohayon MM, Roth TJ. Prevalence of restless legs syndrome and periodic limb movement disorder in the general population. Psychosom Res. 2002;53(1):547-554.

20. Winkelman JW, Finn L, Young T. Prevalence and correlates of restless legs syndrome symptoms in the Wisconsin Sleep Cohort. Sleep Med. 2006;7(7):545-552.

21. Winkelman JW, Shahar E, Sharief I, Gottlieb DJ. Association of restless legs syndrome and cardiovascular disease in the Sleep Heart Health Study. Neurology. 2008;70(1):35-42.

22. Li Y, Walters AS, Chiuve SE, Rimm EB, Winkelman JW, Gao X. Prospective study of restless legs syndrome and coronary heart disease among women. Circulation. 2012;126(14):1689-1694.

23. Molnar MZ, Lu JL, Kalantar-Zadeh K, Kovesdy CP. Association of incident restless legs syndrome with outcomes in a large cohort of US veterans. J Sleep Res. 2015;25:47-56.

24. Wesstrom J, Nilsson S, Sundstrom-Poromaa I, Ulfberg J. Restless legs syndrome among women: prevalence, co-morbidity and possible relationship to menopause. Climacteric. 2008;11(5):422-428.

25. Phillips B, Hening W, Britz P, Mannino D. Prevalence and correlates of restless legs syndrome: results from the 2005 National Sleep Foundation Poll. Chest. 2006;129(1):76-80.

26. Elwood P, Hack M, Pickering J, Hughes J, Gallacher J. Sleep disturbance, stroke, and heart disease events: evidence from the Caerphilly cohort. J Epidemiol Community Health. 2006;60(1):69-73.

27. Walters AS, Rye DB. Review of the relationship of restless legs syndrome and periodic limb movements in sleep to hypertension, heart disease, and stroke. Sleep. 2009;32(5):589-597.

28. Ferini-Strambi L, Walters AS, Sica D. The relationship among restless legs syndrome (Willis-Ekbom Disease), hypertension, cardiovascular disease, and cerebrovascular disease. J Neurol. 2014;261(6):1051-1068.

29. Cuellar NG. The effects of periodic limb movements in sleep (PLMS) on cardiovascular disease. Heart Lung. 2013;42(5):353-360.

30. Pennestri MH, Montplaisir J, Colombo R, Lavigne G, Lanfranchi PA. Nocturnal blood pressure changes in patients with restless legs syndrome. Neurology. 2007;68(15):1213-1218. 
31. Siddiqui F, Strus J, Ming X, Lee IA, Chokroverty S, Walters AS. Rise of blood pressure with periodic limb movements in sleep and wakefulness. Clin Neurophysiol. 2007;118(9):1923-1930.

32. Erden EC, Erden İ, Türker Y, Sivri N, Dikici S, Ozşahin M. Incremental effects of restless legs syndrome on nocturnal blood pressure in hypertensive patients and normotensive individuals. Blood Press Monit. 2012;17(6):231-234.

33. Izzi F, Placidi F, Romigi A, et al. Is autonomic nervous system involved in restless legs syndrome during wakefulness? Sleep Med. 2014; 15(11):1392-1397.

34. Bertisch SM, Muresan C, Schoerning L, Winkelman JW, Taylor JA. Impact of restless legs syndrome on cardiovascular autonomic control. Sleep. 2016;39(3):565-571.

35. Batool-Anwar S, Malhotra A, Forman J, Winkelman J, Li Y, Gao X. Restless legs syndrome and hypertension in middle-aged women. Hypertension. 2011;58(5):791-796.

36. Shi Y, Yu H, Ding D, Yu P, Wu D, Hong Z. Prevalence and risk factors of restless legs syndrome among Chinese adults in a rural community of Shanghai in China. PLoS One. 2015;10(3):1-7. e0121215.

37. Pennestri MH, Montplaisir J, Fradette L, Lavigne G, Colombo R, Lanfranchi PA. Blood pressure changes associated with periodic leg movements during sleep in healthy subjects. Sleep Med. 2013;14(6): $555-561$.

38. Espinar-Sierra J, Vela-Bueno A, Luque-Otero M, et al. Periodic leg movements in sleep in essential hypertension. Psychiatry Clin Neurosci. 1997;51(3):103-107.

39. Wing YK, Zhang J, Ho CK, Au CT, Li AM. Periodic limb movement during sleep is associated with nocturnal hypertension in children. Sleep. 2010;33(6):759-765.

40. De Vito K, Li Y, Batool-Anwar S, Ning Y, Han J, Gao X. Prospective study of obesity, hypertension, high cholesterol, and risk of restless legs syndrome. Mov Disord. 2014;29(8):1044-1052.

41. Högl B, Kiechl S, Willeit J, et al. Restless legs syndrome: a communitybased study of prevalence, severity, and risk factors. Neurology. 2005;64(11):1920-1924.

42. Giannini G, Zanigni S, Melotti R, et al. Association between restless legs syndrome and hypertension: a preliminary population-based study in South Tyrol, Italy. Eur J Neurol. 2014;21(1):72-78.

43. Benediktsdottir B, Janson C, Lindberg E, et al. Prevalence of restless legs syndrome among adults in Iceland and Sweden: lung function, comorbidity, ferritin, biomarkers and quality of life. Sleep Med. 2010;11(10):1043-1048

44. Rothdach AJ, Trenkwalder C, Haberstock J, Keil U, Berger K. Prevalence and risk factors of RLS in an elderly population: the MEMO study. Memory and morbidity in Augsburg elderly. Neurology. 2000; 54(5):1064-1068.

45. Scofield H, Roth T, Drake C. Periodic limb movements during sleep: population prevalence, clinical correlates, and racial differences. Sleep. 2008;31(9):1221-1227.

46. Sakkas GK, Giannaki CD, Karatzaferi C, et al. Current trends in the management of uremic restless legs syndrome: a systemic review on aspects related to quality of life, cardiovascular mortality and survival. Sleep Med Rev. 2015;21:39-49.

47. Giannaki CD, Hadjigeorgiou GM, Karatzaferi C, et al. A single-blind randomized controlled trial to evaluate the effect of 6 months of progressive aerobic exercise training in patients with uraemic restless legs syndrome. Nephrol Dial Transplant. 2013;28(11):2834-2840.

48. Giannaki CD, Sakkas GK, Karatzaferi C, et al. Effect of exercise training and dopamine agonists in patients with uremic restless legs syndrome: a six-month randomized, partially double-blind, placebocontrolled comparative study. BMC Nephrol. 2013;14:194.

49. Giannaki CD, Sakkas GK, Karatzaferi C, et al. Combination of exercise training and dopamine agonists in patients with RLS on dialysis: a randomized, double-blind placebo-controlled study. ASAIO J. 2015;61(6):738-741.

50. Koo BB, Mehra R, Blackwell T, et al. Osteoporotic Fractures in Men (MrOS) Study Group. Periodic limb movements during sleep and cardiac arrhythmia in older men (MrOS sleep). J Clin Sleep Med.2014;10(1):7-11.
51. Mirza M, Shen WK, Sofi A, et al. Frequent periodic leg movement during sleep is an unrecognized risk factor for progression of atrial fibrillation. PLoS One. 2013;8(10):e78359.

52. Gami AS, Pressman G,Caples SM, et al. Association of atrial fibrillation and onstructive sleep apnea. Circulation. 2004;110:364-367.

53. Stuart Miner SE, Pahal D, Nichols L, Darwood A, Nield LE, Wulffhart Z. Sleep disruption is associated with increased ventricular ectopy and cardiac arrest in hospitalized adults. Sleep. 2016;39(4):927-935.

54. Giannaki CD, Zigoulis P, Karatzaferi C, et al. Periodic limb movements in sleep contribute to further cardiac structure abnormalities in hemodialysis patients with restless legs syndrome. J Clin Sleep Med. 2013;9(2):147-153.

55. Hanly PJ, Zuberi-Khokhar N. Periodic limb movements during sleep in patients with congestive heart failure. Chest. 1996;109(6):1497-1502.

56. Javaheri S. Sleep disorders in systolic heart failure: a prospective study of 100 male patients. The final report. Int J Cardiol. 2006;106(1): 21-28.

57. Skomro R, Silva R, Alves R, Figueiredo A, Lorenzi-Filho G. The prevalence and significance of periodic leg movements during sleep in patients with congestive heart failure. Sleep Breath. 2009;13(1): 43-47.

58. Hanly P, Zuberi N. Periodic leg movements during sleep before and after heart transplantation. Sleep. 1992;15(6):489-492.

59. JavaheriS,Abraham WT, BrownC, NishiyamaH, Giesting R, WagonerLE. Prevalence of obstructive sleep apnoea and periodic limb movement in 45 subjects with heart transplantation. Eur Heart J. 2004; 25(3):260-266.

60. Reilly-Spong M, Park T,Gross CR. Poor sleep in organ transplant recipients: self-reports and actigraphy. Clin Transplant. 2013;27(6): 901-913.

61. Molnar MZ, Novak M, Ambrus C, et al. Restless legs syndrome after renal transplantation. Am J Kidney Dis. 2005;45(2):388-396.

62. Manconi M, Ferri R, Zucconi M, et al. Effects of acute dopamineagonist treatment in restless legs syndrome on heart rate variability during sleep. Sleep Med. 2011;12(1):47-55.

63. Palma JA, Alegre M, Valencia M, Artieda J, Iriarte J, Urrestarazu E. Basal cardiac autonomic tone is normal in patients with periodic leg movements during sleep. $J$ Neural Transm (Vienna). 2014;121(4):385-390.

64. Anderson KN, Bhatia KP, Losseff NA. A case of restless legs syndrome in association with stroke. Sleep. 2005;28(1):147-148.

65. Sechi GP, Agnetti V, Galistu P, et al. Restless legs syndrome and periodic limb movements after ischemic stroke in the right lenticulo-striate region. Parkinsonism Relat Disord. 2008;14(2):157-160.

66. Lee JS, Lee PH, Huh K, et al. Periodic limb movements in sleep after a small deep subcortical infarct. Mov Disord. 2005;20(2): 260-261.

67. Ruppert E, Kilic-Huck U, Wolff V, et al. Restless legs syndrome as a first manifestation of a cerebral infarct. J Clin Sleep Med. 2014;10(9): 1037-1038.

68. Schuiling WJ, Rinkel GJ, Walchenbach R, de Weerd AW. Disorders of sleep and wake in patients after subarachnoid hemorrhage. Stroke. 2005;36(3):578-582.

69. Lee SJ, Kim JS, Song IU, An JY, Kim YI, Lee KS. Post-stroke restless legs syndrome and lesion location: anatomical considerations. Mov Disord. 2009;24(1):77-84.

70. Gupta A, Shukla G, Mohammed A, Goyal V, Behari M. Restless legs syndrome, a predictor of subcortical stroke: a prospective study in 346 stroke patients. Sleep Med. 2017;29:61-67.

71. Medeiros CA, de Bruin PF, Paiva TR, Coutinho WM, Ponte RP, de Bruin VM. Clinical outcome after acute ischaemic stroke: the influence of restless legs syndrome. Eur J Neurol. 2011;18(1):144-149.

72. Walters AS, Moussouttas M, Siddiqui F, et al. Prevalence of stroke in restless legs syndrome: initial results point to the need for more sophisticated studies. Open Neurol J. 2010;4:73-77.

73. Park JH, Han SW, Baik JS. Carotid intima-media thickness in patients with idiopathic restless legs syndrome. Eur Neurol. 2012;67(6): 321-325. 
74. Benbir G, Karadeniz D. Periodic leg movements in sleep in patients with supratentorial cerebral infarction. Acta Neurol Belg. 2012; 112(1):27-32.

75. Coelho FMS, Geogsson H, Narayansingh M, Swartz RH, Murray BJ. Higher prevalence of periodic limb movements of sleep in patients with history of stroke. J Clin Sleep Med. 2010;6(5):428-430.

76. Dredla BK, Del Brutto OH, Lee AS, Castillo PR. Willis-Ekbom disease is not associated with poor cardiovascular health in adults. $J$ Negat Results Biomed. 2015;14:17.

77. Schlesinger I, Erikh I, Avizohar O, Sprecher E, Yarnitsky D. Cardiovascular risk factors in restless legs syndrome. Mov Disord. 2009;24(11): 1587-1592.

78. Shell B, Faulk1 K, Cunningham T. Neural control of blood pressure in chronic intermittent hypoxia. Curr Hypertens Rep. 2016;18:19.

79. Foster GE, Poulin MJ, Hanly PJ. Intermittent hypoxia and vascular function: implications for obstructive sleep apnoea. Exp Physiol. 2007; 92:51-65.

80. Lavie L. Obstructive sleep apnoea syndrome- and oxidative stress disorder. Sleep Med Rev. 2003;7:35-51.

81. Siti HN, Kamisah Y, Kamsiah J. The role of oxidative stress, antioxidants and vascular inflammation in cardiovascular disease (a review). Vascul Pharmacol. 2015;71:40-56.

82. Winkelmann J, Lichtner P, Schormair B, et al. Variants in the neuronal nitric oxide synthase (nNOS, NOS1) gene are associated with restless legs syndrome. Mov Disord. 2008;23(3):350-158.

83. Villanueva C, Giulivi C. Subcellular and cellular locations of nitricoxide synthase isoforms as determinants of health and disease. Free Radic Biol Med. 2010;49(3):307-316.

84. Patton SM, Ponnuru P, Snyder AM, Podskalny GD, Connor JR. Hypoxia-inducible factor pathway activation in restless legs syndrome patients. Eur J Neurol. 2011;18(11):1329-1335.

85. Ke Q, Costa M. Hypoxia-inducible factor-1 (HIF-1). Mol Pharmacol. 2006;70(5):1469-1480

86. Semenza GL. The role of hypoxia-inducible factors in oxygen sensing by the carotid body. Adv Exp Med Biol. 2012;758:1-5.

87. Anderson KN, Di Maria C, Allen J. Novel assessment of microvascular changes in idiopathic restless legs syndrome (Willis-Ekbom disease). J Sleep Res. 2013;22(3):315-321.

88. Salminen A, Rimpilä V, Polo O. Peripheral hypoxia in restless legs syndrome (Willis-Ekbom disease). Neurology. 2014;82(21):1856-1861.

89. Salminen AV, Rimpilä V, Polo O. Pramipexole alters thermoregulation in restless legs syndrome. J Clin Sleep Med. 2014;10(12):1325-1329.

90. Koh SY, Kim MS, Lee SM, Hong JM, Yoon JH. Impaired vascular endothelial function in patients with restless legs syndrome: a new aspect of the vascular pathophysiology. J Neurol Sci. 2015;359(1-2):207-210.

91. Trotti LM, Rye DB, De Staercke C, Hooper WC, Quyyumi A, Bliwise DL. Elevated C-reactive protein is associated with severe periodic leg movements of sleep in patients with restless legs syndrome. Brain Behav Immun. 2012;26(8):1239-1243.

92. Weinstock LB, Walters AS. Restless legs syndrome is associated with irritable bowel syndrome and small intestinal bacterial overgrowth. Sleep Med. 2011;12(6):610-613.

93. Hennessy MD, Zak RS, Gay CL, Pullinger CR, Lee KA, Aouizerat BE. Polymorphisms of interleukin-1 beta and interleukin-17alpha genes are associated with restless legs syndrome. Biol Res Nurs. 2014;16(2): $143-151$.

94. Cikrikcioglu MA, Hursitoglu M, Erkal H. Oxidative stress and autonomic nervous system functions in restless legs syndrome. Eur J Clin Invest. 2011;41(7):734-742.

95. Baskol G, Korkmaz S, Erdem F, Caniklioglu A, Kocyigit M, Aksu M. Assessment of nitric oxide, advanced oxidation protein products, malondialdehyde, and thiol levels in patients with restless legs syndrome. Sleep Med. 2012;13(4):414-418.

96. Li Y, Wang W, Winkelman JW, Malhotra A, Ma J, Gao X. Prospective study of restless legs syndrome and mortality among men. Neurology. 2013;81(1):52-59.
97. Yumino D, Wang H, Floras JS, et al. Relation of periodic leg movements during sleep and mortality in patients with systolic heart failure. $\mathrm{Am}$ J Cardiol. 2011;107(3):447-451.

98. Szentkiralyi A, Winter AC, Schurks M, et al. Restless legs syndrome and all-cause mortality in four prospective cohort studies. BMJ Open. 2012;2(6):pii:e001652.

99. Mallon L, Broman JE, Hetta J. Restless legs symptoms with sleepiness in relation to mortality: 20-year follow-up study of a middleaged Swedish population. Psychiatry Clin Neurosci. 2008;62(4): 457-463.

100. Pollak CP, Perlick D, Linsner JP, Wenston J, Hsieh F. Sleep problems in the community elderly as predictors of death and nursing home placement. J Community Health. 1990;15(2):123-135.

101. Araujo SM, de Bruin VM, Nepomuceno LA, et al. Restless legs syndrome in end-stage renal disease: clinical characteristics and associated comorbidities. Sleep Med. 2010;11(8):785-790.

102. Lin $\mathrm{CH}, \mathrm{Wu} \mathrm{VC,} \mathrm{Li} \mathrm{WY,} \mathrm{et} \mathrm{al.} \mathrm{Restless} \mathrm{legs} \mathrm{syndrome} \mathrm{in} \mathrm{end-}$ stage renal disease: a multicenter study in Taiwan. Eur J Neurol. 2013;20(7):1025-1031.

103. Gigli GL, Adorati M, Dolso P, et al. Restless legs syndrome in endstage renal disease. Sleep Med. 2004;5(3):309-315.

104. Lee J, Nicholl D, Ahmed S, et al. The prevalence of restless legs syndrome across the full spectrum of kidney disease. J Clin Sleep Med.2013;9(5):455-459.

105. Merlino G, Lorenzut S, Gigli GL, et al. A case-control study on restless legs syndrome in nondialyzed patients with chronic renal failure. Mov Disord. 2010;25(8):1019-1025.

106. Libório AB, Santos JP, Minete NF, de Diógenes CA, de Farias LA, de Bruin VM. Restless legs syndrome and quality of sleep in patients with glomerulopathy. BMC Nephrol. 2013;14:113.

107. Aritake-Okada S, Nakao T, Komada Y, et al. Prevalence and clinical characteristics of restless legs syndrome in chronic kidney disease patients. Sleep Med. 2011;12(10):1031-1033.

108. Rijsman RM, de Weerd AW, Stam CJ, Kerkhof GA, Rosman JB. Periodic limb movement disorder and restless legs syndrome in dialysis patients. Nephrology. 2004;9(6):353-361.

109. Hohl-Radke F, Aedtner F, Domröse U, Neumann KH, Staedt J. Restless legs syndrome in patients on dialysis for kidney insufficiency: effect of medication. Dtsch Med Wochenschr. 2008;133(3):71-75.

110. La Manna G, Pizza F, Persici E, et al. Restless legs syndrome enhances cardiovascular risk and mortality in patients with end-stage kidney disease undergoing long-term hemodialysis treatment. Nephrol Dial Transplant. 2011;26(6):1976-1983.

111. Lin CH, Sy HN, Chang HW, et al. Restless legs syndrome is associated with cardio/cerebrovascular events and mortality in end-stage renal disease. Eur J Neurol. 2015;22(1):142-149.

112. Lindner A, Fornadi K, Lazar AS, et al. Periodic limb movements in sleep are associated with stroke and cardiovascular risk factors in patients with renal failure. J Sleep Res. 2012;21(3):297-307.

113. Jung HH, Lee JH, Baek HJ, Kim SJ, Lee JJ. Nocturnal hypoxemia and periodic limb movement predict mortality in patients on maintenance hemodialysis. Clin J Am Soc Nephrol. 2010;5(9):1607-1613.

114. Unruh ML, MD, Andrew S. Levey, et al.; for the Choices for Healthy Outcomes in Caring for End-Stage Renal Disease (CHOICE) Study. Restless legs symptoms among incident dialysis patients: association with lower quality of life and shorter survival. Am J Kidney Dis. 2004; 43(5):900-909.

115. Molnar MZ, Szentkiralyi A, Linder A, et al. Restless legs syndrome and mortality in kidney transplant recipients. Am J Kidney Dis. 2007;50(5):813-820.

116. Benz RL, Pressman MR, Hovick ET, et al. Potential novel predictors of mortality in end-stage renal disease patients with sleep disorders. Am J Kidney Dis. 2000;35(6):1052-1060.

117. Stefanidis I, Vainas A, Giannaki CD, et al. Restless legs syndrome does not affect 3-year mortality in hemodialysis patients. Sleep Med. 2015;16(9):1131-1138. 
118. Oh YS, Kim JS, Park IS, et al. Association between nocturnal/supine hypertension and restless legs syndrome in patients with Parkinson's disease. J Neurol Sci. 2014;344(1-2):186-189.

119. Sommerauer M, Imbach LL, Jarallah M, Baumann CR, Valko PO. Diminished event-related cortical arousals and altered heart rate response in Parkinson's disease. Mov Disord. 2015;30(6):866-870.

120. Cuspidi C, Meani S, Salerno M, et al. Cardiovascular target organ damage in essential hypertensives with or without reproducible nocturnal fall in blood pressure. J Hypertens. 2004;22(2):273-280

121. Cicconetti P, Donadio C, Pazzaglia MC, D’Ambrosio F, Marigliano V. Circadian rhythm of blood pressure: non-dipping pattern and cardiovascular disease. Recenti Prog Med. 2007;98(7-8):401-406.
122. Calhoun DA, Harding SM. Sleep and hypertension. Chest. 2010;138(2): 434-443.

123. Eguchi K, Pickering TG, Schwartz JE, et al. Short sleep duration as an independent predictor of cardiovascular events in Japanese patients with hypertension. Arch Int Med. 2008;168(20):2225-2231.

124. Pizza F, Biallas M, Wolf M, Valko PO, Bassetti CL. Periodic leg movements during sleep and cerebral hemodynamic changes detected by NIRS. Clin Neurophysiol. 2009;120(7):1329-1334.

125. Ross R. Atherosclerosis is an inflammatory disease. Am Heart J. 1999; 138(5 Pt 2):S419-S420.

126. Boulanger CM. Endothelium. Arterioscler Thromb Vasc Biol. 2016; 36(4):e26-e31.
Journal of Parkinsonism and Restless Legs Syndrome

\section{Publish your work in this journal}

Journal of Parkinsonism and Restless Legs Syndrome is an online, open access, peer-reviewed journal. The journal publishes review articles, historical reviews, original research articles, case reports, letters to the editor, clinical teaching cases, neuroradiology highlights, neuropathology highlights, neuropsychiatry highlights, autobiographies, conference
Dovepress

proceedings, abstracts and book reviews. The manuscript management system is completely online and includes a very quick and fair peerreview system, which is all easy to use. Visit http://www.dovepress.com testimonials.php to read real quotes from published authors.

Submit your manuscript here: https://www.dovepress.com/journal-of-parkinsonism-and-restless-legs-syndrome-journal 